\title{
8.4 Strategic approach to enterprise personnel management
}

Uncertainty of business conditions, increased dynamism of the marketing environment, unpredictability of competitors requires the use of a strategic approach to management. At the same time, the key to ensuring a strong position of the company in the market is the effectiveness of personnel management - a strategic resource of the company.

Therefore, strategic personnel management becomes an integral part of ensuring the competitiveness of the enterprise.

The generalization of the existing conceptual apparatus has necessitated the improvement of the definition of the concept of "strategic personnel management".

Strategic personnel management of the enterprise is a multifaceted process aimed at optimizing personnel policy and ensuring on this basis the competitiveness of the enterprise in the long run.

The process of strategic personnel management of the enterprise (Fig. 1) consists of three main stages: strategic planning of personnel management activities; strategic organization of personnel management activities; strategic control of personnel management activities. Consider each of these stages [438].

Strategic planning of enterprise personnel management is one of the most important stages of strategic personnel management, because at this stage strategic goals for personnel management are set (i.e targets in the field of personnel management for the long term) and the company's personnel strategy is chosen. established strategic goals for personnel management). 


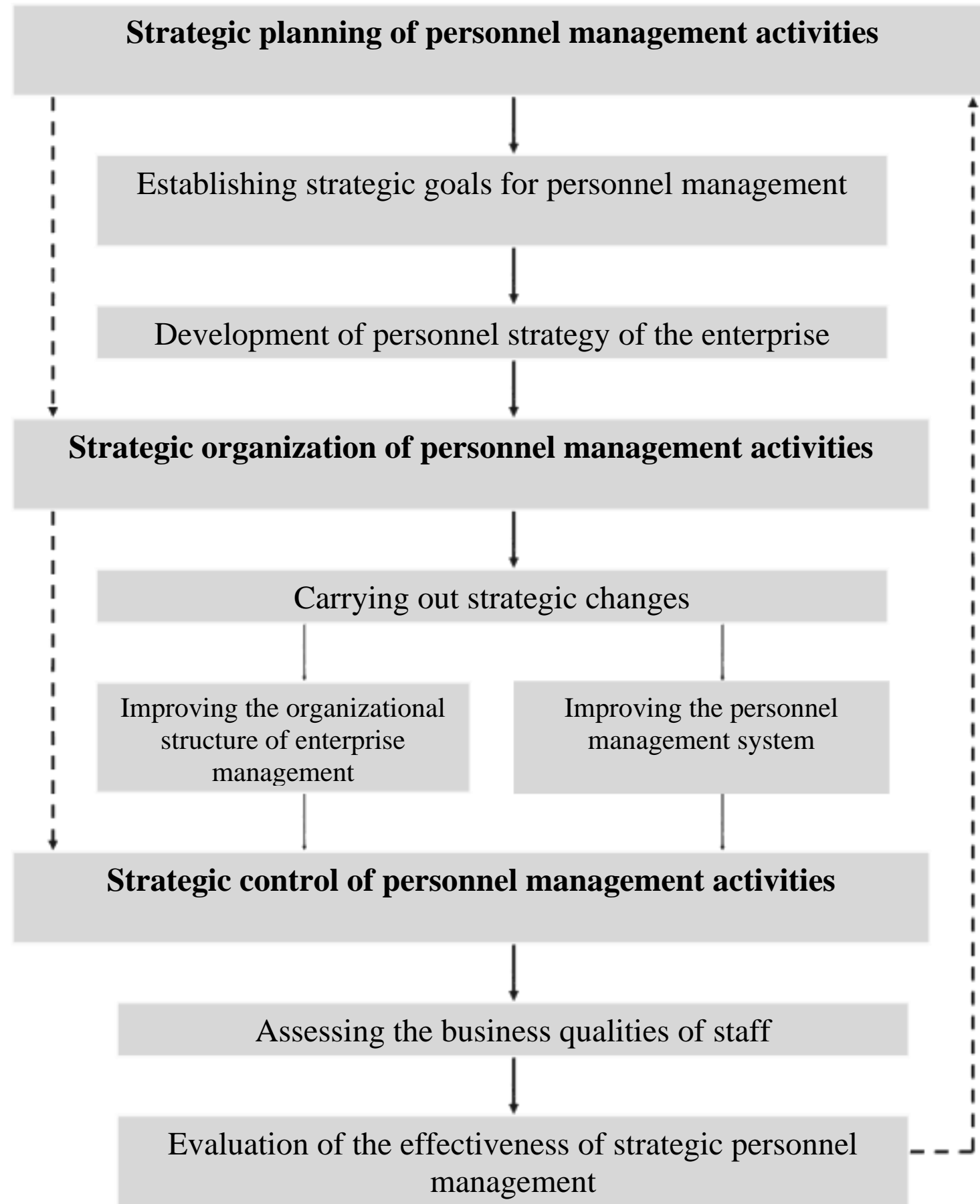

Fig.1. Model of the process of strategic personnel management of the enterprise

Strategic goals of personnel management should be consistent not only with the company's mission, its overall and functional strategic goals, but also to meet the competitive position of the company, as staff is the main source of competitiveness.

When developing strategic goals for personnel management, the company should pay attention to the fact that if its competitive position is very weak, then, first of all, the reasons for this situation should be sought in the personnel management system. 
After setting strategic goals for personnel management should begin to develop a personnel strategy of the enterprise, which, in turn, should be consistent with the strategies of other levels.

The choice of personnel strategy is directly determined by the corporate strategy of the enterprise, i.e. the direction of its development (growth, limited growth, reduction), and business strategies of the enterprise, primarily competitive strategy, which determines what level of staff should be and what competitive advantages it should have.

The second stage of the process of strategic personnel management of the enterprise is the strategic organization of personnel management activities, the key point of which is the implementation of strategic changes in the personnel management system. Any strategic changes involve, first of all, the introduction of certain innovations, but not always the staff is able to adequately perceive the changes taking place in the company [439].

The third stage of the process of strategic personnel management is the strategic control of personnel management activities, which is continuously cyclical and should be carried out at all stages of strategic personnel management.

Strategic control of personnel management activities involves, first of all, the assessment of business qualities of the company's staff. To ensure the competitiveness of strategic personnel management, it is necessary to maintain the optimal quality of information and communication aspects of strategic personnel management, organizational activities for strategic personnel management, motivation and staff development, and corporate culture [440]. The system of ensuring the competitiveness of strategic personnel management of the enterprise is presented in Fig.2.

Let's focus in more detail on staff motivation and development. According to A. Maslow's theory, each person has a certain hierarchy of needs, and the highest level of needs cannot be met until the lower ones are satisfied. There are motivation regulators in the motivation system that can have both positive and negative effects, and the main motivators that come into play after motivation regulators. 


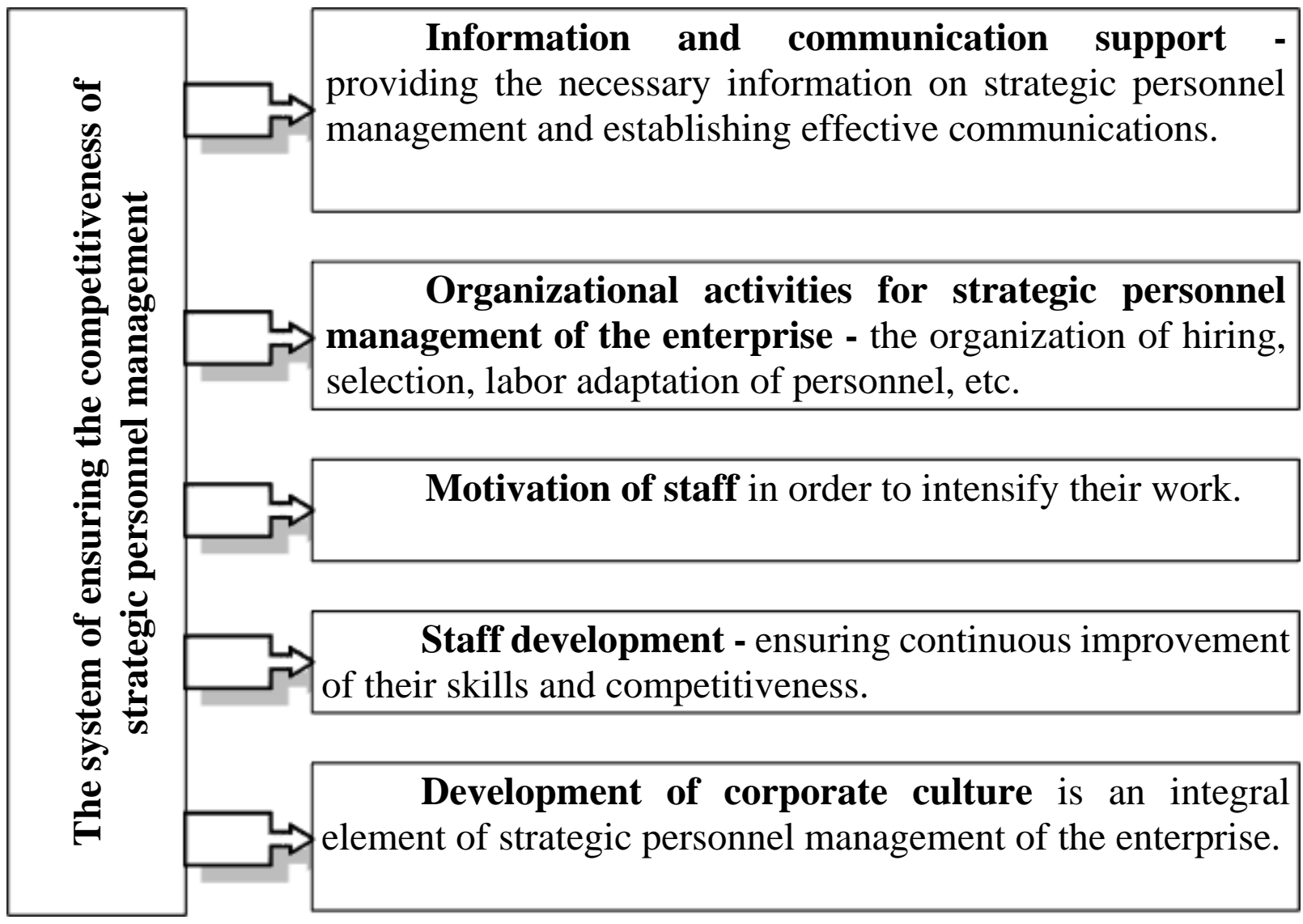

Fig. 2. The system of ensuring the competitiveness of strategic personnel management of the enterprise

Among the regulators of motivation are the following:

- working environment (appropriate organization of workplaces, ensuring optimal working conditions, physical and psychological working conditions);

- reward (material - wages, bonuses, vacation vouchers; intangible - gratitude, flexible work schedule, providing days off and time off);

- sense of security - a sense of belonging to the company, confidence in the future, medical care;

- social protection - social insurance, unemployment insurance, social benefits.

Adherence to these aspects of motivation meets the physiological needs of staff, security needs and part of social needs, and, as a result, encourages employees to perform their duties well. However, if these aspects are not taken into account, then 
there is a demotivation of employees, which leads to lower productivity, increased staff turnover in the enterprise [441].

The main motivators come into play after the motivation regulators. Among the main motivators are:

- social development - the acquisition of a certain social status, promotion;

- personal development - acquisition of new skills and abilities, lifelong learning;

- sense of ownership - participation in the implementation of important projects, participation in decision-making, access to certain information;

- "interest and challenge" - interest, the possibility of self-realization.

These motivators meet the social needs of staff, the need for respect and selfesteem, the need for self-expression and self-actualization.

In addition to an effective system of motivation to ensure the competitiveness of strategic personnel management of the enterprise, it is necessary that the company has established a system of personnel development. At the same time, staff development should be carried out in three directions: professional, social and personal development.

Professional development takes place in the process of acquiring skills and abilities (communication skills and work with the help of means of communication, performing various tasks, customer service), as well as in the process of direct education (university studies, trainings, refresher courses, seminars, conferences). Social development is the result of effective professional development and is manifested primarily in promotion (career growth). The career path of employees can be traditional, networked, through additional skills, double, by adding value to the career, demotion. Each of these career paths is the basis of social development of the employee [442].

Personal development occurs in the process of forming a system of human values, acquiring skills of conflict prevention and resolution, teamwork, as well as through physical, psychological, spiritual, cultural, ethical and aesthetic human development. 
The effectiveness of strategic personnel management of the enterprise is influenced by a number of factors (external and internal) (Table 1), the status of which must be systematically monitored and taken into account in the implementation of the process of strategic personnel management in the enterprise [443].

Table 1

Factors influencing the effectiveness of strategic personnel management of the enterprise

\begin{tabular}{|c|c|}
\hline & $\mathrm{S}$ \\
\hline $\begin{array}{l}\checkmark \text { Legislation on personnel } \\
\text { management. } \\
\checkmark \text { The situation on the labor } \\
\text { market. } \\
\checkmark \quad \text { The situation on the market } \\
\text { of the enterprise. } \\
\checkmark \text { Level of competition } \\
\text { intensity. } \\
\checkmark \text { Efficiency of external } \\
\text { communications of the } \\
\text { enterprise }\end{array}$ & $\begin{array}{ll}\checkmark & \text { Effectiveness of strategic enterprise management. } \\
\checkmark & \text { Effectiveness of strategic planning of personnel } \\
& \text { management activities. } \\
\checkmark & \text { Quality of information support. } \\
\checkmark & \text { Effectiveness of communications in the system of strategic } \\
& \text { personnel management. } \\
\checkmark & \text { Management style. } \\
\checkmark & \text { Competitiveness of staff. } \\
\checkmark & \text { The level of development of corporate culture of the } \\
& \text { enterprise. } \\
\checkmark & \text { Optimality of the motivation system. } \\
\checkmark & \text { Level of use of the personnel development system. } \\
\checkmark & \text { Moral and psychological climate in the team. } \\
\checkmark & \text { Resistance to strategic change. } \\
\checkmark & \text { Propensity of staff to innovate }\end{array}$ \\
\hline
\end{tabular}

A survey of managers and employees of modern enterprises showed that the implementation of strategic personnel management in the practical activities of enterprises faces a number of the following problems [444]:

- Insufficient level of personnel training in the field of strategic management. Modern enterprises do not have managers with deep training in the field of strategic management, and those who have some knowledge in this area do not have sufficient skills to use strategic management tools in practice.

- Resistance to strategic change and innovation. Personnel in most companies are not ready for radical changes in the personnel management system. 
This is primarily due to the fact that people want as much stability as possible, confidence in the future, and, as we know, any strategic changes and innovations carry a number of risks that are difficult to predict in the uncertain environment.

- Lack of financial resources. Significant financial resources are needed for the implementation of strategic changes in the field of strategic personnel management, as the strategic approach requires radical changes in the personnel management system of the enterprise.

- Imperfection of the staff motivation system. Most modern companies use only certain elements of staff motivation, which cannot be an active impetus to intensify staff work. The imperfection of the motivation system is also due to lack of financial and other resources of the enterprise.

- Humiliation of the role of staff in the enterprise. In the strategic approach, staff should be considered as a strategic resource to ensure the competitiveness of the enterprise. However, in most enterprises, personnel are given a secondary role, it is seen only as the labor force needed to perform specific tasks.

- Imperfect legal framework for personnel management. Modern legislation does not reflect perfect mechanisms for personnel management, as a result of which in many enterprises the staff does not have a decent legal protection.

- Insufficient flexibility of organizational management structures. Most modern enterprises have linear, linear-functional or functional organizational management structures that are not able to respond quickly to changes in the external environment. The strategic approach to personnel management involves the introduction of matrix and project organizational management structures that can provide an adequate mechanism for responding to changes in the strategic climate.

- Imperfection of style and methods of personnel management. Many companies have an authoritarian, bureaucratic style of management using mostly organizational and managerial management methods, which does not allow to create a favorable atmosphere for the implementation of the concept of strategic personnel management.

- Insufficient information support of strategic personnel management. Quality information support is a prerequisite for the success of the company in the field of 
strategic personnel management. However, today only a small number of companies have the necessary amount of information on the basis of which it is possible to make and implement adequate management decisions [445].

- Underdevelopment of corporate culture of the enterprise. The consequence of authoritarianism or excessive liberalism in many companies is the insufficient development of corporate culture, the vocation of which should be to strengthen the corporate family, moral and psychological climate in the team, ensuring a sense of ownership of the company, leading to loss of competitive position.

To reduce the level of risk when using a strategic approach to personnel management in enterprises, it is necessary to systematically study the system of strategic personnel management and develop and implement appropriate corrective measures to strengthen the competitive position of the enterprise. 